\title{
1 Modelling facilitation or competition within a root system: importance of the overlap of root depletion and accumulation zones
}

4 Henri de Parseval ${ }^{1}$, Sébastien Barot ${ }^{1}$, Jacques Gignoux ${ }^{1}$, Jean-Christophe Lata ${ }^{1,2}$ and

Xavier Raynaud ${ }^{*}, 1$

${ }^{1}$ Sorbonne Universités, UPMC Univ. Paris 06, CNRS, INRA, IRD, Univ Paris Diderot Paris 07, UPEC, UMR 7618, Institute of Ecology and Environmental Sciences - Paris, Tour 44-45, 4 place Jussieu, 75005 Paris, France

${ }^{2}$ Department of Geoecology and Geochemistry, Institute of Natural Resources, Tomsk Polytechnic University, Lenin Avenue, 30, 634050 Tomsk, Russia

*Corresponding author: xavier.raynaud@upmc.fr

\section{Summary}

Aims: The concept of intra-plant, inter-root competition considers the overlap of nutrient depletion zones around roots, but neglects the spatial pattern of root exudates that can increase nutrient availability. We tested the hypothesis that interactions between nutrient accumulation zones due to exudation by different roots can lead to intra-plant inter-root facilitation.

Methods: We used the PARIS model (Raynaud et al 2008) to simulate phosphorus uptake by a population of roots that are able to increase phosphorus availability by exuding citrate. We carried out several simulations with the same parameters but with increasing root density in order to study out if changes in root densities would alter nutrient uptake per unit root.

24 Results: Emerging relationships between root uptake efficiency and root length density indicated cases of inter-root competition or facilitation. The sizes of the accumulation and depletion zones were calculated to explain these results. Our simulations showed a continuum between cases of inter-root competition and facilitation. Facilitation occurred at low exudation rates, when phosphorus supply was not saturated within the phosphorus depletion zone surrounding roots. Low 
exudation systems led to a lower phosphorus uptake per unit root length, but minimized phosphorus

30 losses in the process.

31 Conclusions: Based on our model, we derived conditions that allowed predicting whether

32 competition, facilitation or no interaction, is the dominant interaction between roots within a root

33 system, based on the different distances to which an isolated root alters P concentration and supply.

35 Key-words: diffusion, exudation, modelling, phosphorus, rhizosphere, spatial distribution

\section{Introduction}

39 Living roots contribute to plant mineral nutrition by two complementary processes: nutrient absorption and exudation. On the one hand, plants are able to adjust the location, surface and uptake rates of their roots to the local concentration in available nutrients (Hodge 2004). On the other hand, they are able to locally increase the availability of mineral nutrients by releasing various products (protons, carbohydrates, secondary metabolites) in the soil surrounding their roots (Dakora and Phillips 2002). For example, experiments and models have shown that local modifications of soil $\mathrm{pH}$ due to the release of organic acids by roots can alter the availability of phosphorus (Hinsinger 2001) and significantly increase plant $P$ uptake at the level of individual plants (Kirk et al, 1999b) or plant community ( $\mathrm{Li}$ et al, 2007). Root exudates can also boost microbial activities, leading to increased mineralization which can, in turn, increase nutrient availability locally (Dijkstra and Cheng 2007; Shahzad et al. 2015).

By taking up nutrients at their surface, roots create diffusion gradients leading to the formation of depletion zones around them (Tinker and Nye, 2000). In the same way, exudates accumulate around roots to form accumulation zones. Nearby roots therefore compete with each other when their respective depletion zones overlap (Ge et al. 2000). Similarly, if exudates increase nutrient availability in the soil surrounding roots, nearby roots could also increase their respective nutrient uptake when exudate accumulation zones overlap. These zones of influence (i.e. depletion and accumulation zones around roots), from which competitive or facilitative interactions can arise, are therefore of fundamental importance for plant nutrition and soil functioning (York et al. 2016).

58 Yet, the consequences of these zones of influence are still poorly understood due to their size which is restricted to short distances around roots (i.e. a few millimetres). In order to tackle these limits, 
several modelling approaches have been developed to explore how root activity can lead to the creation of these root zones of influence, and alter nutrient availability and plant nutrient uptake in the case of (1) single roots (Kirk et al, 1999a; Ptashnyk et al. 2011; Zygalakis and Roose 2012), (2) root systems of single plants (Rubio et al. 2001; Schnepf et al. 2012; Dunbabin et al. 2013) or (3) root systems of different plants in a community (Raynaud et al. 2008). All these studies found that the distance between roots, which results from root system characteristics (size, architecture, root density), could lead to the overlap of these accumulation and/or depletion zones. This could thus alter nutrient availability and plant nutrient uptake in a complex manner: intra-plant, inter-root facilitation adds to intra- and inter-plant competition as a constraint shaping root system architecture and root foraging strategies (Rubio et al. 2001). In this case, net facilitation between roots would occur when the synergistic effect of having a root neighbour is higher than its competitive effect, so that increasing root density increases the absorption of nutrient per unit of root length. Facilitation as a belowground interaction is a quite common concept (Lin et al. 2012). However, to our knowledge, it has never been used at the scale of roots within a single root-system and existing modelling studies have not yet studied how the simultaneous development of accumulation and depletion zones alters rhizosphere nutrient availability and nutrient uptake.

Models of solutes movements around roots indicate that the overlap of depletion or accumulation zones depends on factors controlling diffusion fluxes in soils such as soil physicochemical characteristics, soil water content (Williams and Yanai 1996; Raynaud 2010), as well as the architecture of the root system (e.g. root density). Overlap increases with root density (Rubio et al. 2001; Schnepf et al. 2012) and the consequences of this overlap on plant nutrition depends on the process considered: overlap of nutrient depletion zones should decrease root uptake efficiency (i.e. the amount of nutrient taken up per unit root) whereas overlap of accumulation zones could increase root uptake efficiency if exudates increase nutrient availability. The distance between roots and the respective size of root accumulation and depletion zones should thus determine whether intra-plant, inter-root competition or intra-plant, inter-root facilitation occurs. This latter possibility has so far hardly been mentioned.

Using a simulation model, our objective was to test the above rationale, i.e. to determine whether inter-root facilitation is possible and if so, under which conditions. To do so, we considered the case of a small volume of soil explored by the roots of a single plant individual that takes up a mineral nutrient and can increase its availability through the exudation of solutes. In order to carry out realistic simulations, we have chosen to model the uptake of phosphorus $(\mathrm{P})$ and the changes in its availability through the release of citrate (C) by roots (Hodge, 2004; Fig. 1). The case of citrate 
93 is well documented and relatively simple to model as a direct effect of C concentration on soil

94 physico-chemical properties (Hinsinger 2001). For example, in some soils, phosphorus can be

95 found in the form of phosphate rocks (e.g. apatite) that can release soluble phosphate when in 96 presence of plant-released citrate, due to lower $\mathrm{pH}$ conditions in the plant rhizosphere ( $\mathrm{Li}$ et al, 97 2007). In the modelled soil volume, interactions between roots were assessed by calculating the 98 relationships between plant $\mathrm{P}$ uptake and root length density, as well as $\mathrm{P}$ uptake efficiency (P 99 uptake per unit of root length). As root length density increases, the mean distance between 100 individual roots decreases, which should lead to more overlap of the different accumulation and 101 depletion zones. In this context, we distinguished inter-root competition from facilitation by 102 negative and positive relationships between root length density and P uptake efficiency.

We expected the outcome of our model to depend on all factors that can affect the sizes of root accumulation and depletion zones, i.e. on any factor that affects the inputs, diffusion and losses of the solutes involved. Here, we mostly focused on C exudation rate. Our hypotheses were that: (i) both inter-root competition and facilitation can arise in our model system, (ii) the occurrence of each type of interaction can be explained by patterns of overlap of accumulation and depletion zones and especially (iii) inter-root facilitation should emerge from overlap of accumulation zones with no, or reduced, overlap of P depletion zones. A last hypothesis arising from (iii) is that (iv) inter-root facilitation should occur for intermediate values of root length density.

\section{Material and Methods}

\section{Model description}

114 We modelled the case of a plant taking up P, and exuding C (Fig. 1), using a modified version (see 115 below) of the PARIS model (Raynaud and Leadley 2004; Raynaud et al. 2008) which is an 116 extension of the Barber-Cushman model (Barber and Cushman, 1981) to a set of roots exploring a horizontal layer of soil. The model simulates different rhizosphere processes, including solutes (P

118 and $\mathrm{C}$ ) diffusion and losses, $\mathrm{P}$ absorption at the root surface, $\mathrm{C}$ exudation by roots, and the 119 production of available P from a chemical reaction between C and soil (Kirk et al 1999a; Kirk et al 120 1999b). Model variables and parameters are summarized in Tables 1 and 2 and details of the model 121 equations are given below.

All the modelled processes occur in a $1 \mathrm{~cm}$ thick (parameter $\mathrm{z}$ ) layer of soil, having a surface 123 of 2x2 cm. In contrast to the original PARIS model (Raynaud and Leadley 2004; Raynaud et al. 
124 2008) that considered a hexagonal grid, the soil layer is organized as a 100x100 squared grid of 125 voxels that can be either soil or root. Tests comparing squared and hexagonal geometries as well as 126 the comparison between the diffusion fluxes calculated with these geometries and those obtained from the analytical solution around a single root indicate that, at steady state, results are very robust to the geometry of the grid. Voxel width $(h=0.2 \mathrm{~mm})$ is equal to the diameter of roots and the modelled soil layer is 1 voxel high so that voxels have dimensions $h \times h \times z$. Solute fluxes through soil are thus only horizontal. Roots are assumed to grow vertically down into the soil, and no root branching occurs within the simulated soil volume. As we consider roots having the same geometry as voxels, one root has an exchange surface $(h \times z)$ with the four orthogonal nearest voxel neighbours. We define $d_{R}$ as the root length density within the soil volume $\left(\mathrm{cm} \mathrm{cm}^{-3}\right)$. To eliminate boundary conditions problems and avoid edge effects, we consider the surface modelled as a torus in which top and bottom, as well as left and right edges are connected (periodic boundary condition; Haefner 2012).

Soil water content (parameter $\theta, \mathrm{cm}^{3} \mathrm{~cm}^{-3}$ ) is constant and homogeneous over the modelled soil volume. The diffusion of solutes (phosphorus and citrate) only occurs within the soil liquid phase and is thus a function of $\theta$. For a given solute $i$, the diffusion flux between two adjacent soil voxels $v$ and $w$ is:

$$
F_{(i) \mathcal{v}, w}=-D_{e, i} \frac{\Delta C_{i}}{h}
$$

141 where $D_{e, i}\left(\mathrm{~cm}^{2} \mathrm{~s}^{-1}\right)$ is the effective diffusion coefficient of solutes in the soil and $\Delta C_{i}\left(\mathrm{mmol} \mathrm{cm}^{-3}\right)$ 142 is the concentration difference between voxels $v$ and $w$ (O’Reilly and Beck 2006). $D_{e, i}$ is calculated 143 from $\theta$, the solute diffusion coefficient in pure water $\left(D_{i}, \mathrm{~cm}^{2} \mathrm{~s}^{-1}\right)$, an impedance factor related to the 144 tortuous pathways of water films in the soil (also known as tortuosity factor, $f_{l}$; Olesen et al, 145 2001)and the soil buffer power for the solute considered ( $b_{i}$; van Rees et al. 1990; Raynaud et al. 146 2008):

$$
D_{e, i}=D_{i} \theta f_{l} / b_{i}
$$

147 Soil buffer power ( $b_{i}$; which is related to adsorption/desorption of solute on the soil solid-phase; 148 unitless) depends on soil density ( $\rho), \theta$ and solute distribution coefficient $k_{d, i}$ following:

$$
b_{i}=\theta+\rho k_{d, i}
$$

149 and soil impedance factor $f_{l}$ depends on soil water content and a threshold value below which 150 diffusion ceases due to discontinuous pathways (Olesen et al. 2001): 


$$
f_{l}=1.1\left(\theta-\theta_{\mathrm{th}}\right)
$$

151 where $\theta_{\text {th }}$ represents the soil water content threshold below which diffusion ceases due to 152 discontinuous diffusion pathways.

$153 \quad$ Each voxel loses $\mathrm{P}\left(L_{P}, \mathrm{mmol}_{\mathrm{P}} \mathrm{s}^{-1}\right)$ and $\mathrm{C}\left(L_{C}, \mathrm{mmol}_{\mathrm{C}} \mathrm{s}^{-1}\right)$ at rates $\mu_{P}\left(\mathrm{~s}^{-1}\right), \mu_{C}\left(\mathrm{~s}^{-1}\right)$ that 154 express the disappearance of these solutes due to consumption by other organisms.

All roots are assumed to be identical, except for their position in the soil volume. Roots take 156 up P from adjacent soil voxels at a rate per unit root surface that follows a Michaëlis-Menten 158 equation, with maximum uptake rate $I_{\max }\left(\mathrm{mmol}_{\mathrm{P}} \mathrm{cm}^{-2} \mathrm{~s}^{-1}\right)$ and half saturation constant for uptake $K_{U}\left(\mathrm{mmol}_{\mathrm{P}} \mathrm{cm}^{-3}\right)$, where $C_{P, v}$ is $\mathrm{P}$ concentration in the adjacent soil voxel $v\left(\mathrm{mmol}_{\mathrm{P}} \mathrm{cm}^{-3}\right)$ :

$$
U_{P}=I_{\max } \frac{C_{P, v}}{C_{P, v}+K_{U}} \text {. }
$$

159 Plant $\mathrm{P}$ uptake rate, $A_{P}$, is calculated as the sum of uptake rates of all roots present in the soil: $A_{P}=$ $n_{R} U_{P}$ where $n_{R}$ is the number of roots in the modelled soil volume.

Roots release $\mathrm{C}$ in adjacent voxels at constant rate $e_{c}\left(\mathrm{mmol}_{\mathrm{C}} \mathrm{cm}^{-2} \mathrm{~s}^{-1}\right)$ per unit root surface.

To simulate $\mathrm{P}$ solubilization, available $\mathrm{P}$ is released into each soil voxel at the rate $S_{P}$ $\left(\mathrm{mmol}_{\mathrm{P}} \mathrm{cm}^{-3} \mathrm{~s}^{-1}\right)$ depending on $\mathrm{C}$ concentration in the soil voxel. When $\mathrm{C}$ is not present in a soil voxel, $\mathrm{P}$ supply rate is constant with $S_{P}=S_{\min }$. When C is present, $\mathrm{P}$ supply is increased depending on $\mathrm{C}$ concentration $\left(\mathrm{C}_{\mathrm{C}, \mathrm{v}}\right)$ up to $S_{P}=S_{\max }$ following the relationship:

$$
S_{P}=S_{\text {min }}+\left(S_{\max }-S_{\min }\right) \frac{C_{C, v}}{C_{C, v}+K_{S}}
$$

where $S_{\max }\left(\mathrm{mmol}_{\mathrm{P}} \mathrm{cm}^{-3} \mathrm{~s}^{-1}\right)$ is the soil maximal $\mathrm{P}$ supply rate, $C_{C, v}$ is the C concentration in the soil voxel $v$ and $K_{S}\left(\mathrm{mmol}_{\mathrm{C}} \mathrm{cm}^{-3}\right)$ is a half-saturation constant for P supply (Raynaud et al. 2008).

Overall, solute concentration changes across time in a soil voxel $v$ can be summarized by the differential equations below (see Supplementary Material for the model equation in continuous form), where $w$ corresponds to the four neighbouring soil voxels of $v$ :

$$
\begin{gathered}
\frac{d C_{C, v}}{d t}=(h z) \frac{e_{C}}{h h z}-\mu_{C} C_{C, v}+\frac{1}{h} \sum_{w=1}^{4} F_{(C) v, w} \\
\frac{d C_{P, v}}{d t}=S_{P}-(h z) \frac{U_{P}}{h h z}-\mu_{P} C_{P, v}+\frac{1}{h} \sum_{w=1}^{4} F_{(P) v, w} \quad \text { for voxels adjacent to roots }
\end{gathered}
$$




$$
\begin{gathered}
\frac{d C_{C, v}}{d t}=-\mu_{C} C_{C, v}+\frac{1}{h} \sum_{w=1}^{4} F_{(C) v, w} \\
\frac{d C_{P, v}}{d t}=S_{P}-\mu_{P} C_{P, w}+\frac{1}{h} \sum_{w=1}^{4} F_{(P) v, w}
\end{gathered}
$$

\section{Numerical analysis}

173 Model equations were implemented in JAVA, within the 3Worlds modelling platform (Gignoux et 174 al., 2005; Gignoux et al. 2011). Individual roots were randomly distributed within a 2-dimensional rectangular grid of cells representing the modelled layer of soil. Solutes diffusion and root-soil interactions (absorption and exudation) were programmed as reusable sub-routines plugged into the 3Worlds core application.

All parameter values used for simulations are given in Table 2. $\mathrm{P}$ and $\mathrm{C}$ parameters were taken from different literature sources (see Table 2 for details). We modelled rhizosphere processes for increasing number of roots $\left(n_{R}\right)$, with values ranging from 1 to 600 roots in a $1 \times 2 \times 2 \mathrm{~cm}^{3}$ soil volume (14 different values of $n_{R}$ ). This corresponds to root length densities $d_{R}$ ranging from 0.25 $\mathrm{cm} \mathrm{cm}^{-3}$ to $150 \mathrm{~cm} \mathrm{~cm}^{-3}$ (although unrealistic, this upper value was useful for the interpretation of our results). Because voxels can be either soil or root but not both, the increase in root density thus reduces the amount of soil modelled, and eventually the total P supply of soil. In the case where supply in all soil voxels is $S_{P}=S_{\max }$, this reduction in $\mathrm{P}$ supply is at most $6 \%$ between the two extremes of the chosen range of root densities, and less than $1 \%$ for densities below $25 \mathrm{~cm} \mathrm{~cm}^{-3}$. Roots were placed randomly within the $2 \times 2 \mathrm{~cm}$ modelled surface. To avoid the risk that our results depend on a particular root spatial distribution, 5 different maps were used for each root length density value (e.g. 5x14=70 maps in total). The model outputs obtained from these different maps are shown as points in Figs. 3 and 5. As the exudation rate of $\mathrm{C}\left(e_{C}\right)$ affects the size of exudation rhizospheres (Raynaud 2010), our simulations were done for several values of this parameter (Table 2).

The kinetics and mass-transport equations were solved simultaneously. Model equations (Eqs. 7 and 8) were solved numerically using Forward Time Centered Space (FTCS) finite difference scheme (Press et al. 2007) until all fluxes of P and C reached steady-state (e.g., P supply $\left(S_{P}\right)$ becomes equal to the sum of plant $\mathrm{P}$ uptake $A_{P}$ and $\mathrm{P}$ losses $L_{P}$, and the rate of $\mathrm{C}$ liberated by all roots equals the rate of $\mathrm{C}$ lost from the soil). The time step for integration was $10 \mathrm{~s}$. For each simulation, the influx, stocks and outflux of solutes were calculated for both P and C (Table 1). We 
defined $\mathrm{P}$ uptake efficiency $U E_{P}$ as the quantity of $\mathrm{P}$ taken up by unit of root length:

$$
U E_{P}=\frac{A_{P}}{d_{R} V}
$$

200

201

202

203

204

205

206

207

208

209

210

where $A_{P}$ represents total $\mathrm{P}$ absorption and $V$ is the simulated soil volume.

\section{Assessment of the sizes of root influence regions on soil properties}

Our modelling framework produces concentration maps for available $\mathrm{P}$ and $\mathrm{C}\left(C_{P}, C_{C}\right)$, as well as maps of $\mathrm{P}$ supply $\left(S_{P}\right)$ that can be used to measure the spatial influence of roots on soil concentrations and supply. In order to get a simpler description of the size of the region upon which roots have some influence, we have used these calculated maps to assess the sizes of root zones of influence. We considered that (i) the distance to which a root can alter soil properties depended on the process considered (i.e. different distances were calculated for $C_{P}, C_{C}$, and $S_{P}$ ) and (ii) the result of root influence on soil properties was the creation of gradients that could be used to estimate these distances.

In the case of a single root, defining a "limit" between the volume of soil influenced by the root and bulk soil has to be drawn arbitrarily from the gradient (Hinsinger et al. 2009). For citrate concentrations $C_{C}$, this limit was set to a modification by roots $>5 \%$ compared to bulk soil values (C accumulation zone, Fig. 2, top left). In the case of P supply $S_{P}$, we considered two distinct limits: the first corresponding to an increase $>5 \%$ of the bulk soil supply (total supply zone), similar to $C_{C}$, the second corresponding to 95\% of soil maximum supply $S_{P}$ (“saturated zone”, Fig. 2, middle left). Considering these two limits for P supply allowed a better description of soil supply heterogeneity. Finally, the size of the $\mathrm{P}$ depletion zone was calculated as the distance to the maximum $\mathrm{P}$ concentration from each root (Fig. 2, bottom left). These different limits calculated from simulations with a single root were used to calculate the radii of the citrate accumulation zone $\left(r^{1} C\right)$, the total supply zone $\left(r^{1}\right.$ s05), the saturated zone $\left(r^{1}\right.$ s95) and the P depletion zone $\left(r_{P}^{1}\right)$ for an isolated root. Considering different values for these limits (e.g. 1\% instead of 5\%) modified the sizes of the different zones considered but did not qualitatively changed the results.

When several roots are present, gradients around individual roots can overlap, so that all the simulated soil volume can be under the influence of one or more roots and the above limits cannot be used. Moreover, if the accumulation or depletion zones of two neighbouring roots overlap, concentrations and supply will not be monotonic along the line between these two roots (Fig. 2, right panels). We thus assumed that the "territory" of a root can be defined as the distance from that 
root within which the gradient of concentration or supply was monotonic (e.g. citrate concentration decreases to a minimum with increasing distance from the root). This distance no longer measures the size of the zone of influence of a single root, but rather indicates the level of overlapping and interaction between the zones of influence of single roots. Because all roots have identical parameters in a simulation, if all neighbouring root zones of influence overlap, the average radius of the territory of a root is equal to the average half distance between 2 roots for a given root density $r_{\max }\left(d_{R}\right)=\sqrt{1 /\left(\pi d_{R}\right)}$

In each simulated map, because root positions were drawn randomly, some roots could be isolated from others and thus develop full concentration gradients, whereas others would interact with each other. We thus calculated the average radius of root territory as the distance from a root within which (1) the concentration (or supply flux) was above the limits defined for the isolated root rhizosphere (see above) or (2) the gradient of concentration or supply from that root was monotonic. The corresponding variables, $t_{C}$ (citrate exudation), $t_{S 05}$ (P supply), $t_{S 95}$ (saturated $\mathrm{P}$ supply) and $t_{P}$ (P depletion) thus quantify the radius of these territories. Depending on the spatial distribution of roots and the root density in the simulated maps, these distances can take any values between the zone of influence size for a single root when a root is isolated from others $\left(r_{C}^{1}, r_{S 05}^{1}, r_{S 95}^{1}, r_{P}^{1}\right)$, and $r_{\max }\left(d_{R}\right)$ when all neighbouring roots interact.

\section{Results}

\section{Phosphorus fluxes depend on root density and exudation rates}

Soil $P$ supply- In all simulations, total $\mathrm{P}$ supply $S_{P}$ increased with root length density $d_{R}$ up to a maximum value that depended on $S_{\max }$ (Fig. 3a). The slight decrease observed for very high $d_{R}$ values was due to the absence of P supply in the voxels occupied by roots, which reduced the total amount of soil voxels that can supply P (see Methods). The relationship between $S_{P}$ and $d_{R}$ also depended on $\mathrm{C}$ exudation rate $e_{C}$, with overall lower values for low $\mathrm{C}$ exudation rate $e_{C}$.

Plant $P$ uptake and $P$ losses from soil- Total $P$ uptake $A_{P}$ always increased with root length density $d_{R}$ and exudation rates $e_{C}$, without reaching saturation (not shown). On the contrary, $\mathrm{P}$ losses $L_{P}$ displayed a unimodal shape (Fig. 3b): an increase from low to intermediate $d_{R}$ as a direct consequence of higher $\mathrm{P}$ supply and a decrease once the maximum supply is reached while $\mathrm{P}$ uptake $A_{P}$ carries on increasing. 
$P$ uptake efficiency- Because available $\mathrm{P}$ can be taken up by roots or lost through microbial consumption, roots could not take all available $\mathrm{P}$. With the chosen values for $\mathrm{P}$ loss rate $\mu_{P}$, the relative proportion of absorbed $\mathrm{P}$ by all roots $\left(A_{P}\right)$ over $\mathrm{P}$ supply $\left(S_{P}\right)$ increased with root length density $d_{R}$ from 0.015 to 0.5 , and was higher for smaller $e_{C}$ values (Fig. 3c). The efficiency of $\mathrm{P}$ uptake by single roots ( $U E_{P}$, Eq. 9) varied depending on $C$ exudation rate $e_{C}$ (Fig. 3d): for high exudation rates, $U E_{P}$ always decreased with root density whereas in the case of the lower exudation rate tested, $U E_{P}$ first increased and then decreased.

\section{Patterns of accumulation and depletion zone sizes determine inter-root competition or facilitation}

Figure 2 gives an example of a $\mathrm{C}$ concentration profile around a single root and the corresponding $\mathrm{P}$ supply profile, as well as the calculated influence zone radii $r_{C}{ }^{1}, r_{S P 05}{ }^{1}$ and $r_{S P 95}{ }^{1}$. Due to the nonlinearity of the relationship between $C$ concentration $C_{C}$ and P supply $S_{P}$ (Eq. 6), the calculated C accumulation zone radius, $r_{C}{ }^{1}$, was not a good descriptor of the volume upon which roots alter $\mathrm{P}$ supply in the soil. We thus focused on territory sizes of P supply ( $\left.t_{s 05}\right)$, P supply saturation ( $\left.t_{S 95}\right)$ and $\mathrm{P}$ depletion $\left(t_{P}\right)$. In order to illustrate the links between nutrient concentration and territory sizes, Figure 4 maps the changes in P supply around roots, as well as the extent of $\mathrm{P}$ depletion zones in two maps differing in root length densities and for the three exudation rates tested. The chosen root length densities in these maps correspond to the two contrasted patterns observed for P root uptake efficiency in Figure 3d: a decrease of $U E_{P}$ between low and high root length density for high exudation rate whereas $U E_{P}$ increased between these two values at low exudation rate.

Figure 4 shows that for a citrate exudation rate of $10^{-8} \mathrm{mmol} \mathrm{cm}^{-2} \mathrm{~s}^{-1}$, the whole soil volume was influenced by roots for P supply, even at low $d_{R}$. At high $d_{R}$, P supply was maximized in the whole modelled soil volume. The pattern was similar for a $\mathrm{C}$ exudation rate of $10^{-9} \mathrm{mmol} \mathrm{cm}^{-2} \mathrm{~s}^{-1}$, although very small regions of bulk soil are still present at low $d_{R}$ and $\mathrm{P}$ supply is not maximized over the whole soil volume. C exudation rates lower than $10^{-9} \mathrm{mmol} \mathrm{cm}^{-2} \mathrm{~s}^{-1}$ yielded a slightly different pattern, leaving large part of the soil unaffected by roots at low $d_{R}$, whereas most soil was affected by roots at high $d_{R}$ but with supply values $<S_{\max }$. In particular, at low $d_{R}$, P depletion zones around roots were relatively isolated, whereas most $\mathrm{P}$ concentration were under the influence of roots at high $d_{R}$ values.

Figure 5 shows the average territory radius around one root as a function of $d_{R}$ and $e_{C}$ and suggests that this extent followed a similar pattern for all three territory types along the gradient of 
291 root length density $d_{R}$ : whatever the territory considered, average territory radii was constant for

292 low $d_{R}$ values and then decreased with increasing $d_{R}$. (Fig. 5). A territory radius equal to $r_{\max }\left(d_{R}\right)$

293 thus indicates that zones of influence of neighbouring roots overlap so that roots mutually influence

294 the solute concentrations in each other's surroundings. The only exception for this general pattern

295 was the radius of saturated $\mathrm{P}$ supply territory $t_{S 95}$, which was slightly greater at intermediate $d_{R}$

296 values compared to low $d_{R}$ values in the case of intermediate and low values of C exudation (barely

297 visible on Fig. 5, but significant). This increase occurs because close roots increase the saturation of

298 P supply between them, thus increasing the size of their saturation rhizosphere without necessarily

299 merging or overlapping them (see Fig. 4, mid left panel).

301 Discussion

302 Most of our hypotheses were confirmed by our study: (i) facilitation between roots of the same root 303 system can occur when the availability of a nutrient (e.g. phosphorus) depends on the exudation of a 304 chemical factor (e.g. citrate) by roots; (ii) facilitation or competition depend on the degree of 305 overlap between the rhizospheres of individual roots; (iv) facilitation occurs at intermediate levels 306 of root density above which $\mathrm{P}$ uptake efficiency decreases, i.e. inter-root competition increases. 307 Hypothesis (iii) was only partly confirmed: the overlap of P depletion zones around roots accounted 308 well for the emergence of inter-root competition, but the overlap of $\mathrm{C}$ accumulation zones was not 309 relevant to fully explain the emergence of inter-root facilitation.

310 To our knowledge, our study is the first exploring the mechanisms through which 311 facilitation within the root system of a single plant can occur. Our results suggest that the ability of 312 a plant to increase $\mathrm{P}$ availability through exudation does not prevent inter-root competition, but 313 rather creates a continuum between cases of inter-root competition and inter-root facilitation. 314 Studies on root foraging strategies have not, to date, considered the consequence of root exudation 315 on nutrient supply (Ge et al. 2000; Cahill and McNickle 2011; Pagès 2011; but see Schnepf et al. 316 2012) and have not distinguished the respective scales of root exudation and nutrient uptake 317 (McNickle et al. 2009). Our study suggests that exudation of solutes by neighbouring roots can 318 dramatically alter nutrient availability near the root system so that increasing root density might not 319 necessarily lead to a decrease in root uptake efficiency. Still, our study explored a relatively simple 320 case and the robustness of our results and their implications for the understanding of root foraging 321 strategies remain to be thoroughly studied both through modelling and experiments. Below, we 322 focus on the mechanisms that lead to the emergence of inter-root facilitation and how they could be 
323 generalized. Then, we analyse the implications of the variability of inter-root interactions for root

324 foraging strategies.

\section{Mechanisms leading to the emergence of facilitation between roots}

326 Above all, the possibility of facilitation between roots depends on the mechanisms by which roots 327 are able to locally increase the availability of nutrients. Our model allows tracking the creation of 328 spatial heterogeneity in nutrient stocks and fluxes from individual root activity. In particular, the model allows distinguishing gradients of $\mathrm{P}$ supply from the gradients of $\mathrm{C}$ concentration that created them. The model thus allows extrapolation of the concept of root zone of influence to fluxes of $\mathrm{P}$ whereas it is more often applied to stocks (concentrations of solutes, partial pressure of gas etc.; Hinsinger et al. 2009). Because the model assumes that $\mathrm{P}$ supply is a saturating function of $\mathrm{C}$ concentration, we distinguished two different territories for P supply: the "saturated territory" ( $\left.t_{S 95}\right)$, i.e. the volume of soil in which the effect of a root is maximum and in which an increase of exudate concentration has no effect, and the total P supply territory ( $\left.t_{S 05}\right)$ that corresponds to the whole volume in which roots increase P supply.

We first discuss how facilitation and competition can occur in the case of two neighbouring roots and then extend this discussion to a population of roots randomly distributed on a 2D plane. First, consider two identical roots separated by the distance $2 d$, with root zones of influence radii $r_{P}^{1}, r_{S 05}^{1}$ and, $r_{S 95}^{1}$ (see Supporting information Fig. S1 for an illustration). Because these radii are those of the zones of influence of single roots (see Material and Method section), they do not depend on the distance $d$. These two roots compete for P if their P depletion zones overlap so that they do not compete for P if:

$$
r_{P}^{1}<d(\text { condition } 1) \text {. }
$$

Because exudates are released from roots and diffuse into the soil, $\mathrm{P}$ supply can change along the distance $2 d$. Both roots mutually alter soil P supply in their vicinity if their total supply zones overlap, which occurs when:

$$
r_{S 05}^{1}>d \quad \text { (condition 2). }
$$

However, if the two roots increase $C$ concentrations sufficiently enough to saturate $\mathrm{P}$ supply up to distance $d$, P supply is constant and equal to $S_{\max }$ across the whole distance $2 d$ and adding more exudate to the soil does not increase P supply (Fig. 4b). This becomes similar to a case where P supply is constant in the whole soil volume. In such case, P uptake of a root competing with others only depends on its uptake rate (Raynaud and Leadley 2004) and facilitation does not occur. 
354 A necessary condition to observe facilitation is thus that the saturated P supply zones of both roots

355 do not overlap, which corresponds to:

$$
r_{S 95}^{1}<d \quad \text { (condition 3) }
$$

If conditions 2 and 3 allow identifying cases in which facilitation can occur, the intensity of 358 the facilitation depends on the degree to which total P supply zones of the two roots overlap, as the 359 benefits of root proximity only occurs in the overlapping region. This yields two more conditions on $\mathrm{P}$ depletion zones and total $\mathrm{P}$ supply zones. First, in order for the root to benefit from the increase in supply, the $\mathrm{P}$ depletion zones must include parts of the region where supply is increased (i.e. where total supply zones overlap), which corresponds to:

$$
r_{P}^{1}>2 d-r_{S 05}^{1} \quad \text { (condition 4) }
$$

Second, if the $\mathrm{P}$ depletion zone of a root $\left(r_{P}^{1}\right)$ is smaller than the zone over which this root brings $\mathrm{P}$ supply to its maximum value ( $r^{1}$ s95), part of the $\mathrm{P}$ made available by exudates is out of reach for this particular root, and changes in exudate concentration near this root do not lead to changes in P supply (Fig. 4a). Thus, the condition:

$$
r_{P}^{1}>r_{S 95}^{1} \quad \text { (condition 5) }
$$

is necessary for facilitation to occur. However, even when condition 5 is met, if $r_{P}^{1} \approx r_{S 95}^{1}$ an increase in root density only leads to a limited increase in supply because increase in supply only occurs in the region between $r^{1} S 95$ and $r_{P}^{1}$. Thus, facilitation is important only if $r_{P}^{1}>>r^{1}$ S95 and the greater the ratio $r_{P}^{1} / r^{1} s 95$, the greater the facilitation.

In the case of a population of roots randomly distributed on a 2D plane, the half distance 374 between 2 neighbouring roots is, on average, $r_{\max }\left(d_{R}\right)$ but can be larger or smaller for some roots. 375 Replacing $d$ by $r_{\max }\left(d_{R}\right)$ thus gives average conditions for facilitation to occur. However, because 376 half distances between 2 neighbouring roots vary around this mean, facilitation can occur before the above conditions are met. In our simulations, we found that facilitation started for $r^{1}{ }_{S 05}>r_{\max }\left(d_{R}\right) / 2$ 378 at low exudation rates (see Supporting Information Fig. S2). Overall, because citrate concentration gradient around roots depends on exudation rates (Raynaud 2010), these different conditions explain why facilitation only occurs at low exudation rates (where P maximum supply only occur in the immediate vicinity of roots) whereas only competition occurs for higher exudation rates 382 (because the whole soil is at maximum supply).

Our results are consistent with the classical observation, usually at the plant community 384 scale, that facilitative interactions are more frequent in resource-poor systems (Bruno et al. 2003; 
385 Kéfi et al. 2008). In our model, the base level of P supply ( $\left.S_{\min }\right)$ was very low compared to its 386 saturation value so that exudation was the only way for roots to access to available P. If this base 387 level was to increase (i.e. the share of directly available nutrients increases), facilitation should be 388 less frequent. The shape of the relation between exudate concentration and P supply might also have 389 some influence on our results. However, we believe that whenever P supply increases with exudate 390 concentration and saturates above a given exudate concentration, qualitatively similar results should 391 be obtained as the conditions described above should still hold. Moreover, as our model has shown 392 that the relative size of root zones of influence is crucial in determining the type of root interaction, 393 any parameter affecting their size (e.g., soil water content, diffusion of exudates, etc., see Raynaud 394 2010) should influence the type of interaction between roots within root systems. As some of these parameters vary a lot on the short term, e.g. soil water content (Loague 1992), the same root system should switch from facilitation to competition over short time-scales. The value we chose for soil water content in our analysis is an intermediate value, so that our simulations should reflect an intermediate case of root system functioning. Ultimately, studies on inter-root interactions (facilitation or competition) should articulate the different time-scales of root-soil interactions, from the short-time changes of soil properties and root activities to the long-term dynamic of root growth and demography (Hodge et al. 2009). For example, dauciform or cluster roots (Shane and Lambers 2005, Shane et al. 2006) allow plants to increase their absorption of P. This is likely to arise because these roots have very high exudation rates and saturate the soil volume in carboxylates. However, the facilitation mechanism we suggest with our model could also be influential. Our rationale should also be tested for more complex patterns of root spatial distributions (e.g. aggregation) that emerge from dynamic root architecture models (e.g. Pagès 2011). In particular, such models should better take into account the fact that roots are not parallel and that portions of roots that exude and take up nutrients are not necessarily the same (Doussan et al. 2003).

Whether these extended concepts of root zones of influence could be used in other studies 410 and especially in the field has to be discussed. Much progress has been made in the in situ 411 observation of gradients around roots (Hinsinger et al. 2009) but measuring supply and their degree 412 of saturation would require a very fine knowledge of the stocks of unavailable nutrients and their 413 potential of release. Still, our results suggest that the assessment of the P supply and saturated P 414 supply zones is crucial to understand interactions within the root system, although the function that 415 converts exudate concentration into a nutrient supply could strongly condition the outcome of root 416 interactions. 
418 increases the availability of P by a chemical reaction (Hinsinger 2001), it is based on very general 419 mechanisms (e.g. solute diffusion, nutrient uptake, etc.) and should apply to the roots of any plant in 420 any soil. We used it here to highlight the existence of new possible interactions between 421 neighbouring roots but the frequency of positive interactions between roots should be assessed by 422 parametrizing the model for different case studies. Moreover, this theoretical approach could be 423 generalized to other nutrients, whose availability depends on the release of molecules by roots, or 424 on the interactions between roots and soil microorganisms. For example, mineralisation of organic 425 nitrogen can depend on interactions between plant roots and soil micro-organisms, through the 426 release of root exudates (Raynaud et al. 2006; Shahzad et al. 2015). Similarly, biological 427 nitrification inhibition (Lata et al. 2004; Subbarao et al. 2006) by some grass species is due to the 428 release by roots of molecules that inhibit microbial ammonium oxidation. However, to be 429 generalized to such cases, a precise knowledge of the molecules involved and the processes and 430 time scales that lead to the increase in nutrient availability is needed. Similarly in cases in which 431 soil micro-organisms are involved, the spatial distribution of microorganisms with respect to root 432 spatial distribution (Compant et al. 2010) could also influence interactions between roots.

\section{Implications for root foraging strategies}

434 The concept of intra-plant inter-root competition was originally formulated in a context where the 435 carbon cost of nutrient acquisition was to be evaluated: inter-root competition within the root 436 system decreases the benefits of a root when it is close to another one (Ge et al. 2000; Rubio et al. 437 2001). When only root absorption is considered, a good proxy of the carbon cost of nutrient 438 acquisition is root length density and we used it in our definition of P uptake efficiency. This 439 approximation can be used when comparing root systems differing by their root length density but 440 not by their levels of root exudation rates (Lynch and Ho 2005). In this context, our results suggest 441 that cases of intra-plant, inter-root facilitation should favour local root proliferation where root 442 length density increases nutrient uptake efficiency. By contrast, inter-root competition should 443 favour sparser root systems that limit competitive interactions between roots (Ge et al. 2000). The 444 building of root systems thus not only depends on the presence of other plant competitors but also 445 on plant-created heterogeneity, that can both can lead to an increase (due to facilitation) or decrease 446 (due to competition) of root length density (Rubio et al. 2001). Similarly, facilitation between roots 447 of the same plant individual could favour dense root systems limiting their exploration of the soil 448 volume (de Parseval et al. 2016). 
450 the amount of $\mathrm{P}$ taken up by unit of root length was lowered (due to the low exudates concentration 451 in soils), but where P losses were also minimised. Indeed, increasing exudation increases the 452 availability of $\mathrm{P}$ which should also lead to an increase of losses through microbial immobilization. 453 This suggests the existence of a gradient of strategies, in essence similar to the classical $\mathrm{r} / \mathrm{K}$ 454 gradient. This gradient would span from a very fast exploitation of the nutrient pool, associated to 455 high exudation rates but also high losses, to a slow but more effective exploitation of the pool, 456 associated with low exudation rates and low losses (Boudsocq et al. 2011; Reich 2014): indeed, 457 more exudation leads to competition and a loss of efficiency, as measured by the amount of 458 resource invested to absorb mineral nutrients. However, the different levels of root exudation tested 459 in our model are not equivalent to the nutrient uptake efficiency as we have defined it. For a 460 relevant comparison, the assessment of the relative cost of root construction and functioning is 461 needed, as well as that of exudation to determine the total cost of P uptake (Lynch and Ho 2005). A 462 low exudation strategy, that leads to inter-root facilitation, should be advantageous compared to a 463 high exudation strategy only if the cost of exudation is high compared to that of root absorption, e.g. 464 when complex molecules have to be synthesized.

465 Rationales based on the carbon cost of nutrient acquisition do not always account well for 466 root foraging strategies. In the context of competition between roots, the use of game theory has 467 proved useful (O’Brien and Brown 2008). For example, even if the proliferation of roots implies a 468 high carbon cost relative to the benefits (increase in nutrient absorption), this behaviour also leads 469 to a competitive advantage for the root system with higher root length density (Robinson et al., 470 1999; Raynaud and Leadley 2004; Craine et al. 2005). Although our results focus on interactions 471 between roots from a single root system, they could easily be generalized to interactions between 472 roots from different root systems and suggest that roots of one species could benefit from the 473 proximity of roots of another species that would increase nutrient supply in their vicinity (Raynaud 474 et al. 2008). The possibility of positive interactions between root systems or individual plants could 475 be taken into account through new game theory root models, especially if one takes into account the 476 ability of self/non self-recognition by roots (Gruntman and Novoplansky 2004). Somehow, our 477 model suggests a mechanism that could account for some of the predicted and documented cases of 478 inter-plant facilitation (Callaway et al. 2002).

479 One important application of root foraging studies is the identification of roots traits that 480 could be selected to enhance crop yields and/or sustainability (Lynch 2011). However, the study of 481 crop species often neglected the role of exudation (Pagès 2011), whose importance seems to be 482 minimised when nutrients are brought in high concentration and in a highly available form, as it is 
483 often the case in agroecosystems. Studies about mechanisms by which plants increase the 484 availability of nutrients (Chapman et al. 2006) have mainly focused on wild species from nutrient485 poor environment. Agroecosystems are high yielded but lead to huge losses of mineral nutrients. 486 One reason for that is the massive use of mineral fertilizers. Another reason is that high yield 487 varieties have been selected and that these varieties are probably able to quickly absorb available 488 nutrients but do not impede losses of nutrient. Our results suggest that selecting species that limit 489 nutrient losses and foster root facilitation either intra- or inter-plants could reduce the need of 490 fertilizers while maintaining high yields (Loeuille et al. 2013).

\section{Acknowledgements}

493 We thank Shayne Flint and Ian Davies for their help in designing the model on 3Worlds. We thank 494 Eric Lateltin and reviewers for constructive comments on earlier versions of the manuscript. This 495 work was supported by the French Agence Nationale de la Recherche, grant number ANR-07-CIS7496001 (3Worlds project).

\section{References}

499 Barber SA, Cushman JH (1981) Nutrient uptake model for agronomic crops. In: Iskander IK (ed) 500 Modelling wastewater renovation land treatment. Wiley, New York, pp. 382-409.

501 Boudsocq S, Barot S, Loeuille N (2011) Evolution of nutrient acquisition: when adaptation fills the 502 gap between contrasting ecological theories. P Roy Soc B-Biol Sci, 278:449-457.

503 Bruno JF, Stachowicz, JJ, Bertness MD (2003) Inclusion of facilitation into ecological theory. 504 Trends Ecol Evol 18:119-125.

505 Cahill JF, McNickle GG (2011) The behavioral ecology of nutrient foraging by plants. Annu Rev 506 Ecol Evol Syst, 42:289-311.

507 Callaway RM, Brooker R, Choler P, Kikvidze Z, Lortie CJ, Michalet R, Paolini L, Pugnaire FI, 508 Newingham B, Aschehoug ET et al. (2002) Positive interactions among alpine plants increase with 509 stress. Nature, 417:844-848.

510 Chapman SK, Langley JA, Hart SC, Koch, GW (2006) Plants actively control nitrogen cycling: 511 uncorking the microbial bottleneck. New Phytol, 169:27-34. 
512 Compant S, Clément C, Sessitsch A (2010) Plant growth-promoting bacteria in the rhizo- and 513 endosphere of plants: Their role, colonization, mechanisms involved and prospects for utilization. 514 Soil Biol Biochem 42:669-678.

515 Craine JM, Fargione JE, Sugita S (2005) Supply pre-emption, not concentration reduction, is the 516 mechanism of competition for nutrients. New Phytol 166:933-940.

517 Dakora F, Phillips D (2002) Root exudates as mediators of mineral acquisition in low-nutrient 518 environments. Plant Soil 245:35-47.

519 Dijkstra FA, Cheng W (2007) Interactions between soil and tree roots accelerate long-term soil 520 carbon decomposition. Ecol Lett 10:1046-1053.

521 Doussan C, Pagès L, Pierret A (2003) Soil exploration and resource acquisition by plant roots: an 522 architectural and modelling point of view. Agronomie 23:419-431.

523 Dunbabin VM, Postma JA, Schnepf A (2013) Modelling root-soil interactions using three524 dimensional models of root growth, architecture and function. Plant Soil 372:93-124.

525 Ge Z, Rubio G, Lynch JP (2000) The importance of root gravitropism for inter-root competition and 526 phosphorus acquisition efficiency: results from a geometric simulation model. Plant Soil 218:159527171.

528 Gignoux J, Davies ID, Flint SR, Zucker J-D (2011) The ecosystem in practice: Interest and 529 problems of an old definition for constructing ecological models. Ecosystems 14:1039-1054.

530 Gignoux J, Davies ID, Hill DRC (2005) 3Worlds: a new platform for simulating ecological 531 systems. 1st Open International Conference on Modelling and Simulation, Clermont-Ferrand, 532 France, pp. 49-64.

533 Gruntman M, Novoplansky A (2004) Physiologically mediated self/non-self discrimination in roots. 534 Proc Nat Acad Sci USA 101:3863-3867.

535 Haefner JW (2005) Modeling biological systems: Principles and applications. $2^{\text {nd }}$ ed. Springer 536 Science \& Business Media.

537 Hinsinger P (2001) Bioavailability of soil inorganic P in the rhizosphere as affected by root-induced 538 chemical changes: a review. Plant Soil 237:173-195.

539 Hinsinger P, Bengough AG, Vetterlein D, Young IM (2009) Rhizosphere: biophysics, 540 biogeochemistry and ecological relevance. Plant Soil 321:117-152. 
541 Hodge A (2004) The plastic plant: root responses to heterogeneous supplies of nutrients. New 542 Phytol 162:9-24.

543 Hodge A, Berta G, Doussan C, Merchan F, Crespi M (2009) Plant root growth, architecture and 544 function. Plant Soil 321:153-187.

545 Jones DL, Darrah PR (1994) Role of root derived organic acids in the mobilization of nutrients 546 from the rhizosphere. Plant Soil 166:247-257.

547 Kéfi S, Van Baalen M, Rietkerk M, Loreau M (2008) Evolution of local facilitation in arid 548 ecosystems. Am Nat 172:1-17.

549 Kirk GJD, Santos EE, Findenegg GR (1999a) Phosphate solubilization by organic anion excretion 550 from rice (Oryza sativa L.) growing in aerobic soil. Plant Soil 211:11-18.

551 Kirk GJD, Santos EE, Santos MB (1999b) Phosphate solubilization by organic anion excretion from 552 rice growing in aerobic soil: rates of excretion and decomposition, effects on rhizosphere $\mathrm{pH}$ and 553 effects on phosphate availability and uptake. New Phytol 142:185-200.

554 Lata J-C, Degrange V, Raynaud X, Maron P-A, Lensi R, Abbadie L (2004) Grass populations 555 control nitrification in savanna soils. Funct Ecol, 18:605-611.

556 Li L, Li SM, Sun J-H, Bao X-G, Zhang H-G, Zhang F (2007) Diversity enhances agricultural 557 productivity via rhizosphere phosphorus facilitation on phosphorus deficient soils. Proc Nat Acad 558 Sci USA, 104:11192-11196.

559 Lin Y, Berger U, Grimm V, Ji Q (2012) Differences between symmetric and asymmetric facilitation 560 matter: exploring the interplay between modes of positive and negative plant interactions. $J$ Ecol $561 \quad 100: 1482-1491$.

562 Loague K (1992) Soil water content at R-5. Part 1. Spatial and temporal variability. J Hydrol 563 139:233-251.

564 Loeuille N, Barot S, Georgelin E, Kylafis G, Lavigne C (2013) Eco-evolutionary dynamics of 565 agricultural networks: Implications for sustainable management. Adv Ecol Res, 49:339-435.

566 Lynch JP (2011) Root phenes for enhanced soil exploration and phosphorus acquisition: tools for 567 future crops. Plant Physiol 156:1041-1049.

568 Lynch JP, Ho MD (2005) Rhizoeconomics: Carbon costs of phosphorus acquisition. Plant Soil 569 269:45-56.

570 McNickle GG, St Clair CC, Cahill JF (2009) Focusing the metaphor: plant root foraging behaviour. 
572 Nielsen KL, Lynch JP, Jablokow AG, Curtis PS. 1994. Carbon cost of root systems: an architectural 573 approach. Plant Soil 165: 161-169.

574 O’Brien EE, Brown JS (2008) Games roots play: effects of soil volume and nutrients. $J$ Ecol, 575 96:438-446.

576 O’Reilly RC, Beck JM (2006) A family of large-stencil discrete Laplacian approximations in three 577 dimensions. Int J Numer Meth Engineer, 1-16.

578 Oburger E, Jones DL, Wenzel WW. 2011. Phosphorus saturation and pH differentially regulate the 579 efficiency of organic acid anion-mediated P solubilization mechanisms in soil. Plant Soil 341: 363580382.

581 Olesen T, Moldrup P, Yamaguchi T, Rolston DE (2001) Constant slope impedance factor model for 582 predicting the solute diffusion coefficient in unsaturated soil. Soil Science 166:89-96.

583 Pagès L (2011) Links between root developmental traits and foraging performance. Plant Cell 584 Environ, 34:1749-1760.

585 de Parseval H, Abbadie L, Barot S, Gignoux J, Lata J-C, Raynaud X (2016) Explore less to control 586 more: why and when should plants limit the horizontal exploration of soil by their roots? Oikos $587 \quad 125: 1110-1120$.

588 Press WH, Teukoisky SA, Vetterling WT, Flannery BP, Teukolsky S (2007) Numerical Recipes, 589 3rd ed. Cambridge University Press.

590 Ptashnyk M, Roose T, Jones DL, Kirk GJD (2011) Enhanced zinc uptake by rice through 591 phytosiderophore secretion: a modelling study. Plant, Cell Environ 34:2038-2046.

592 Raynaud X (2010) Soil properties are key determinants for the development of exudate gradients in 593 a rhizosphere simulation model. Soil Biol Biochem 42:210-219.

594 Raynaud X, Jaillard B, Leadley PW (2008) Plants may alter competition by modifying nutrient 595 bioavailability in rhizosphere: a modeling approach. Am Nat 171:44-58.

596 Raynaud X, Lata J-C, Leadley PW (2006) Soil microbial loop and nutrient uptake by plants: a test 597 using a coupled C:N model of plant-microbial interactions. Plant Soil 287:95-116.

598 Raynaud X, Leadley PW (2004) Soil characteristics play a key role in modelling nutrient 599 competition in plant communities. Ecology 85:2200-2214.

600 van Rees KCJ, Comerford NB, Rao PSC (1990) Defining soil buffer power: Implications for ion 
601

602 Reich PB (2014) The world-wide 'fast-slow' plant economics spectrum: a traits manifesto. $J$ Ecol 603 102:275-301.

604 Robinson D, Hodge A, Griffiths BS, Fitter AH (1999) Plant root proliferation in nitrogen-rich 605

diffusion and nutrient uptake modelling. Soil Sci Soc Am J 54:1505-1507. patches confers competitive advantage. Proc Roy Soc B-Biol Sci 266:431-435.

Rubio G, Walk T, Ge Z, Yan X, Liao H, Lynch JP (2001) Root gravitropism and below-ground competition among neighbouring plants: a modelling approach. Ann Bot, 88:929-940.

Schnepf A, Leitner D, Klepsch S (2012) Modeling phosphorus uptake by a growing and exuding root system. Vadose Zone J doi:10.2136/vzj2012.0001.

Shahzad T, Chenu C, Genet P, Barot S, Perveen N, Mougin C, Fontaine S (2015) Contribution of exudates, arbuscular mycorrhizal fungi and litter depositions to the rhizosphere priming effect induced by grassland species. Soil Biol Biochem 80:146-155.

Shane MW, Cawthray GR, Cramer MD, Kuo J, Lambers H (2006) Specialized “dauciform” roots of Cyperaceae are structurally distinct, but functionally analogous with “cluster” roots. Plant, Cell Environ, 29:1989-1999.

Shane MW, Lambers H (2005) Cluster roots: A curiosity in context. Plant Soil, 274:101-125.

Subbarao GV, Rondon M, Ito O, Ishikawa T, Rao IM, Nakahara KI, Lascano CE, Berry WL (2006) Biological nitrification inhibition (BNI) - is it a widespread phenomenon? Plant Soil, 294:5-18.

Tinker PB, Nye PH (2000) Solute movement in the rhizosphere. Oxford University Press, Oxford, UK, 444p.

Vanysek P (2000) Ionic conductivity and diffusion at infinite dilution. In: Lide DR, ed. CRC Handbook Of Chemistry And Physics. CRC Press, 1-3.

Williams M, Yanai RD (1996) Multi-dimensional sensitivity analysis and ecological implication of a nutrient uptake model. Plant Soil 180:311-324.

York LM, Carminati A, Mooney SJ, Ritz K, Bennett MJ (2016) The holistic rhizosphere: integrating zones, processes, and semantics in the soil influenced by roots. J Exp Bot 67:3629-3643.

Zygalakis KC, Roose T (2012) A simple mathematical model for investigating the effect of cluster roots on plant nutrient uptake. Eur Phys J-Spec Top 204:103-118. 


\section{Tables}

630 Table 1: Model variables: symbols, definitions and units

631 Table 2: Model parameter values used in simulations 


\section{Figures Legend}

633 Figure 1: Schematic representation of the modelled system. Two concentrations of solutes within 634 the soil solution are quantified by $C_{P}$ (phosphorus) and $C_{C}$ (citrate) variables. Large white arrows 635 represent fluxes for these soil solutes: the supply of phosphorus to the soil solution $\left(S_{P}\right)$, its losses $636\left(L_{P}\right)$ or absorption by roots $\left(A_{P}\right)$, citrate exudation from roots $\left(e_{C}\right)$ and its losses $\left(L_{C}\right)$. The small arrow represents the modulation of phosphorus supply by citrate concentration $C_{C}$ (see Eq. 6). All

638 these processes are spatially explicitly quantified within a 2D grid (see Fig. 4).

639 Figure 2: Description of the gradients around a root. Hatched zones indicate the position of root 640 rhizoplanes. Left: Zone of influence limits for citrate accumulation $C_{C}$ (top), P supply $S_{P}$ (mid) and 641 P depletion $C_{P}$ (bottom) around a root isolated from interaction with neighbours. Vertical dashed 642 lines show the respective rhizosphere sizes $\left(r^{1} C, r^{1}\right.$ so5, $r^{1}$ s95, and $\left.r_{P}^{1}\right)$ and horizontal dashed lines 643 show the threshold values used to calculate them (see text). Right: Territory for citrate 644 concentration $C_{C}$ (top), $\mathrm{P}$ supply $S_{P}$ (mid) and $\mathrm{P}$ concentration $C_{P}$ (bottom) when rhizospheres 645 overlap. Note the difference in the $\mathrm{x}$-axis scales between the left and right panels. Vertical dashed 646 lines show the respective territory sizes $\left(t_{C}, t_{S 05}, t_{S 95}\right.$, and $\left.t_{P}\right)$ and horizontal dashed lines indicate 647 the threshold values used to calculate the rhizosphere sizes.

648 Figure 3: Relationships between root density ( $d_{R}$, log scale) and different variables quantifying 649 phosphorus fluxes in the root-soil system: average soil phosphorus supply ( $S_{P}$, panel a) and losses 650 ( $L_{P}$, panel b), the ratio of phosphorus absorbed relative to its supply ( $A_{P} / S_{P}$, panel c, log scale) and 651 phosphorus root uptake efficiency ( $U E_{P}$, panel d). We focus here on the effect of the variation of 652 exudation rates $e_{C}$ (see legend panel a). In panel a, the dashed line at the top of the graphic 653 corresponds to the maximum value of $\mathrm{P}$ supply $\left(S_{\max }\right)$ in the whole modelled soil volume. The 654 decrease at high root density is due to the reduction in soil volume (see Methods). In all panels, 655 points correspond to model outputs for different spatial distribution of roots with a given root 656 density and exudation rate. Solid lines represent the means of simulations for a given root density 657 and exudation rate.

658 Figure 4: Maps of rhizospheres calculated from simulations for the three exudation rates $e_{c}$ tested 659 and two root length densities $d_{R}$. Bulk soil is shown in black and the saturation territory ( $\left.t_{S P 95}\right)$ is 660 shown in white. The light gray/dark gray gradient illustrates the variation in supply within the 661 supply territory $\left(t_{S 05}\right)$. Dotted lines delimit phosphorus depletion territories $\left(t_{P}\right)$. Roots are figured 662 by a black dot. See Fig. 2 for the criteria chosen to determine the border of each territory.

663 Figure 5: Estimation of average zone of influence diameters of single roots for phosphorus 
664 depletion (a), phosphorus supply (b) and phosphorus supply saturation (c) as a function of root 665 length density $d_{R}$. Cases of intra-plant, inter-root competition are presented by open circles and 666 squares, and the case of inter-root facilitation by filled triangles. Dashed lines correspond to the 667 maximum rhizosphere size $\left(r_{\max }=\sqrt{\left(1 /\left(d_{R} \pi\right)\right)}\right)$ as a function of $d_{R}$. In all panels, points 668 correspond to the calculated diameter of zones of influence for different spatial distribution of roots 669 with a given root density and exudation rate. Solid lines represent the means of these diameters for a 670 given root density and exudation rate. 


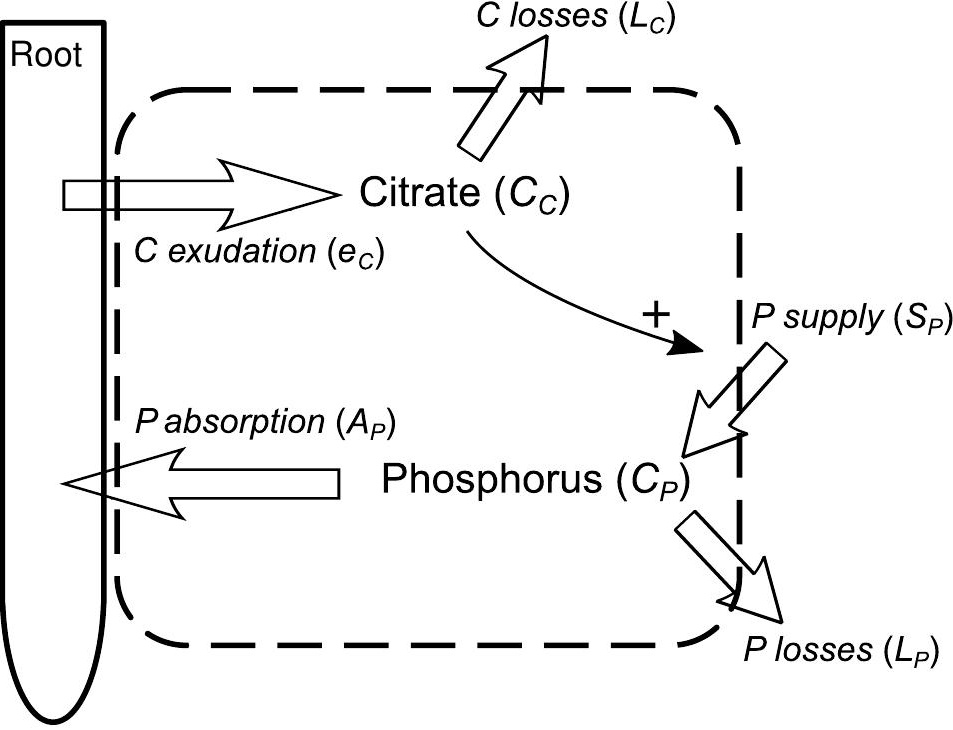


Single Root

\section{Root 1}
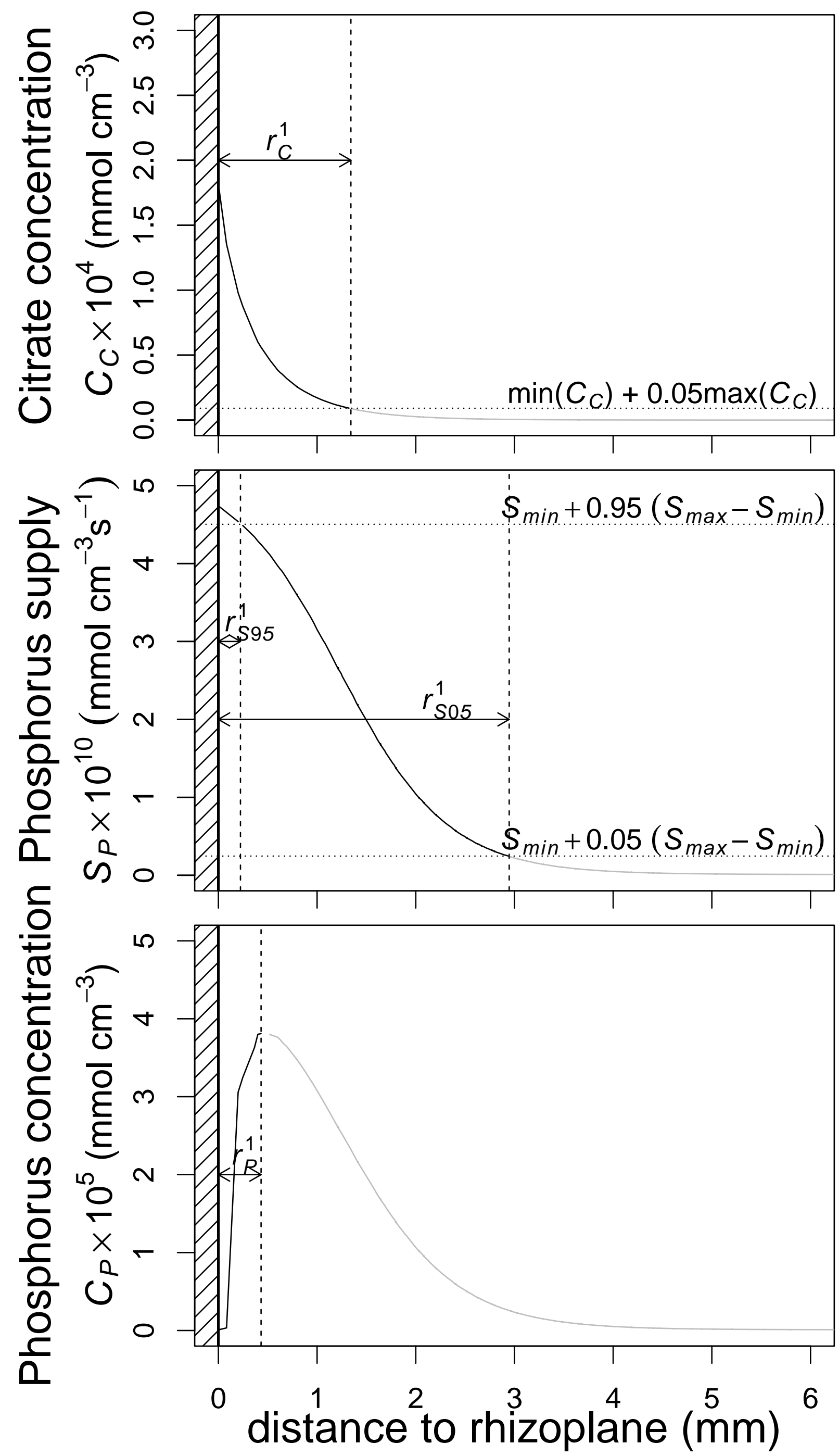

Two Root

Root 1

Root 2
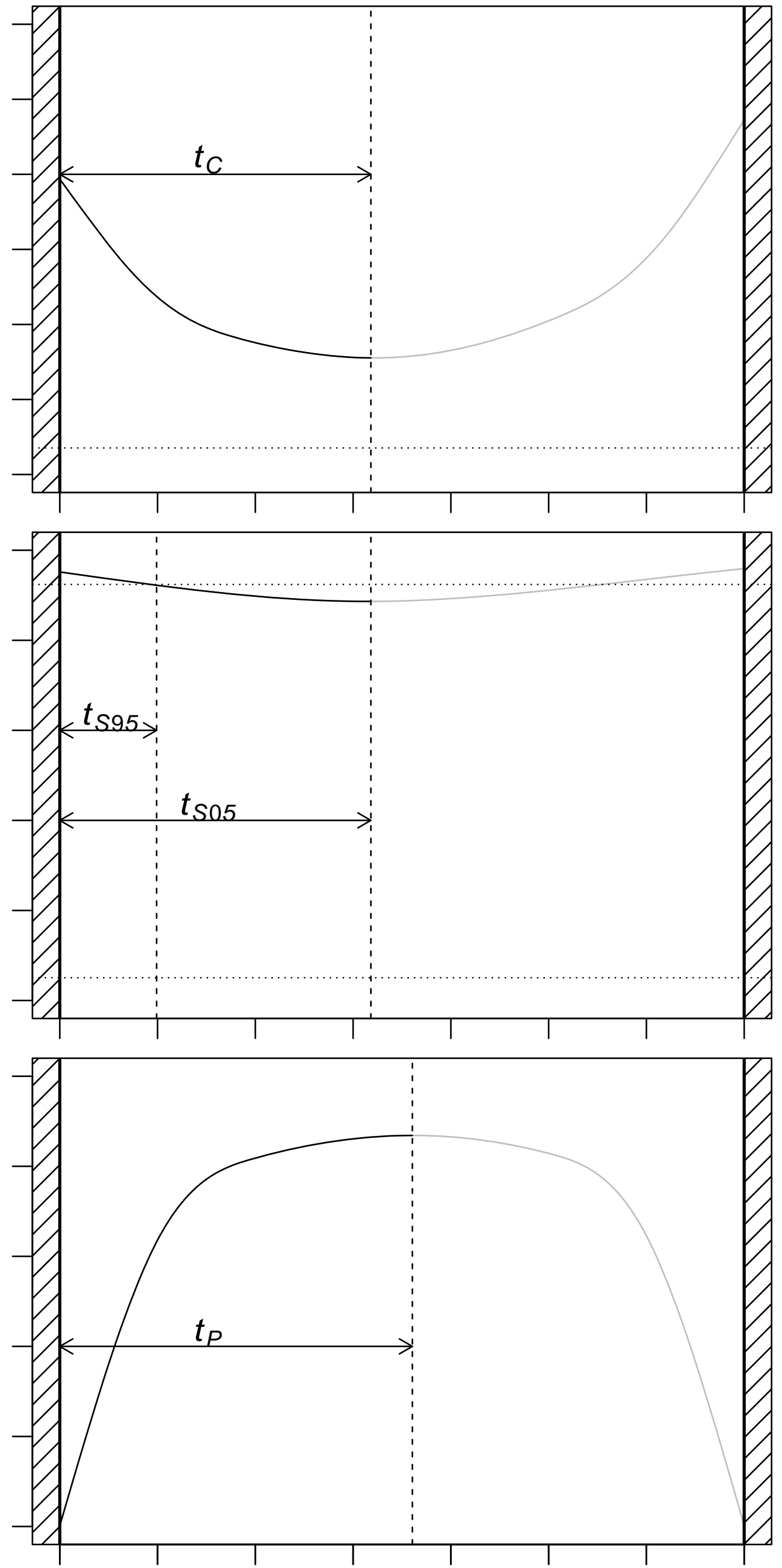

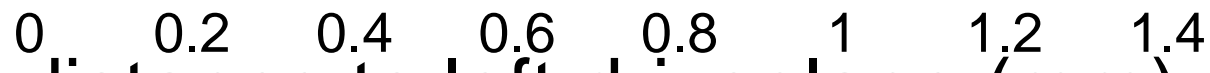
distance to left rhizoplane (mm) 


\section{Average $P$ supply}

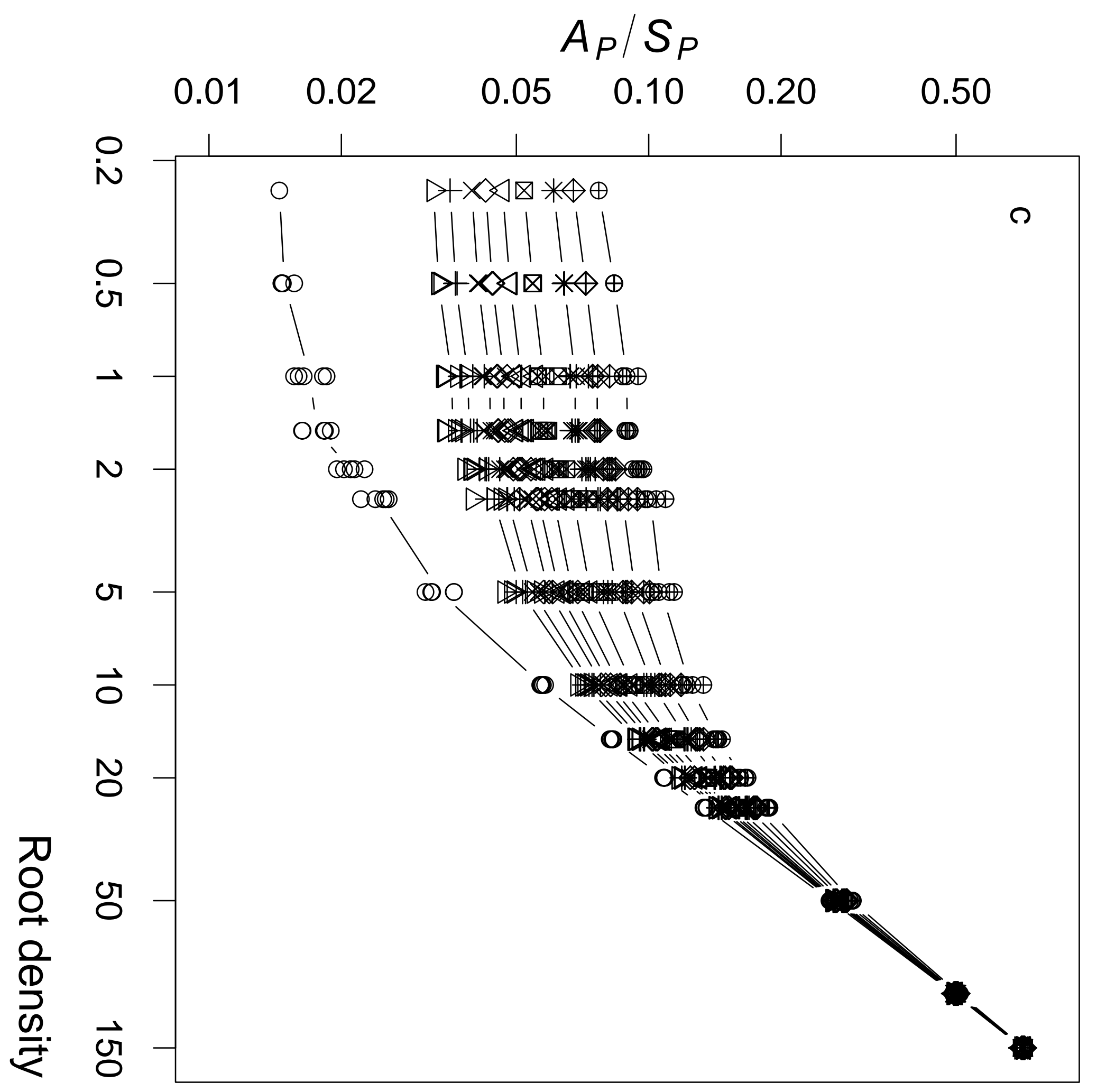

$\frac{2}{D}$

के

Root $P$ uptake efficiency

$U E_{P}\left(\mathrm{nmol} \mathrm{cm}{ }^{-1} \mathrm{~h}^{-1}\right)$

0.0070

0.0080

0.0090

0.0100

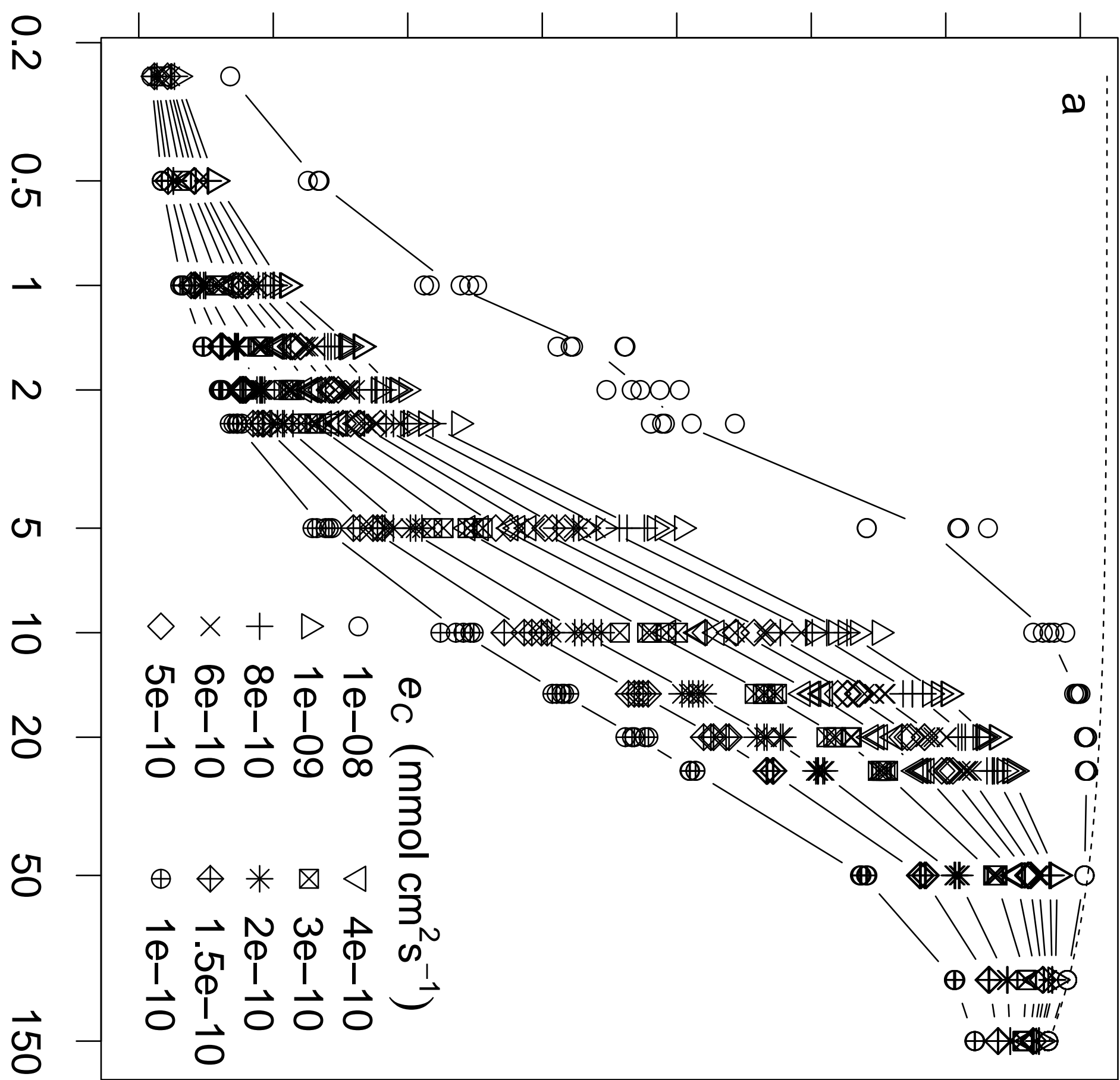

3
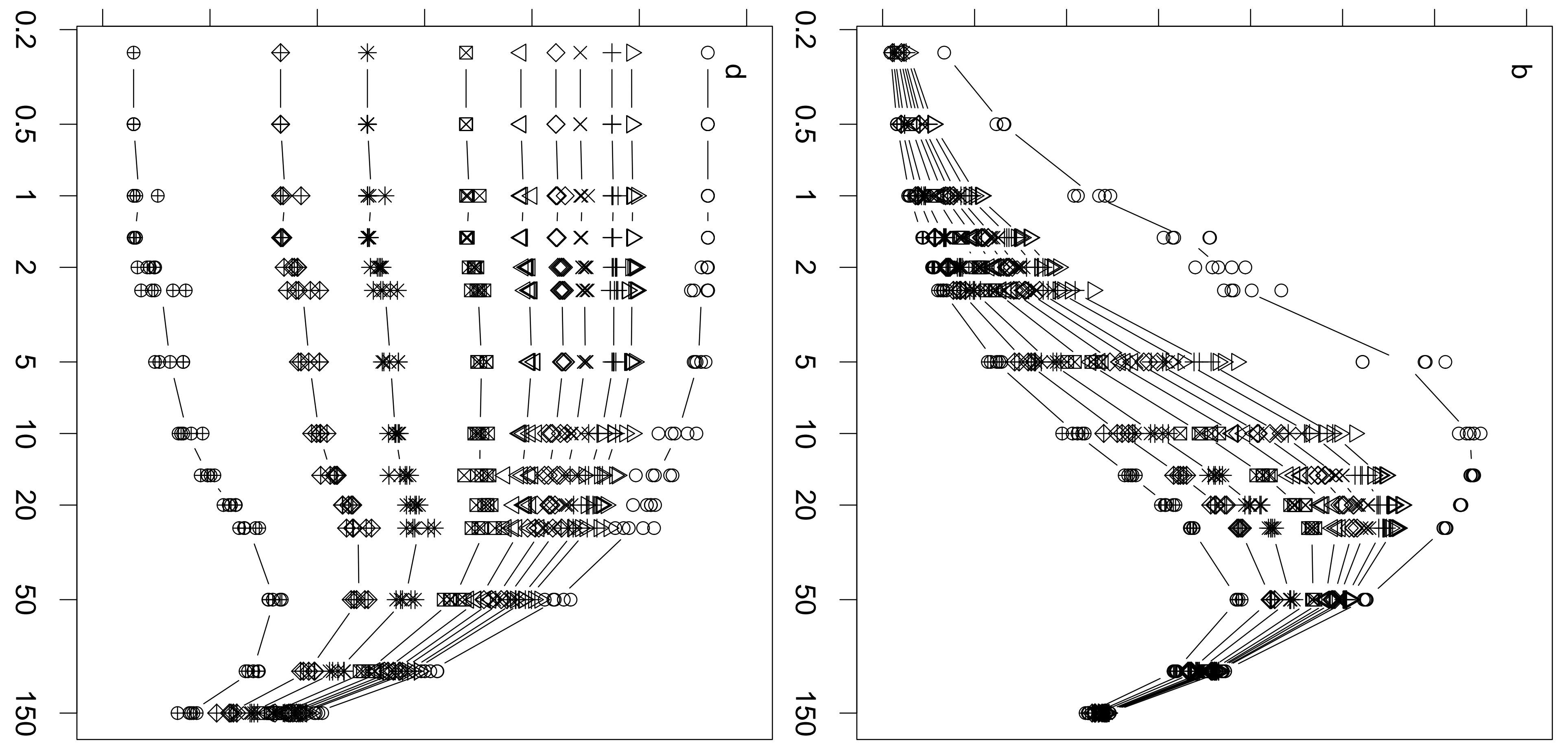

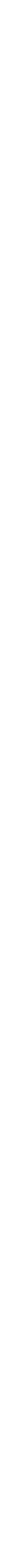
Supporting Information

Article title: Facilitation or competition within a root system depends on the overlap of root depletion and accumulation zones: a mechanistic model

Authors: H. de Parseval, S. Barot, J. Gignoux, J.-C. Lata and X. Raynaud* 


\section{Mathematical development of the PARIS model:}

The model considers the diffusion of citrate $(\mathrm{C})$ and phosphate $(\mathrm{P})$ in soil with effective diffusion coefficients $D_{e, C}$ and $D_{e, P}$ (Eq. 2). When C is present in the soil, it increases the concentration of $\mathrm{P}$ by $S_{P}$ following Eq. 6. We assume that $\mathrm{C}$ and $\mathrm{P}$ disappear from the soil at rates $\mu_{C}$ and $\mu_{P}$, respectively. The rate of change in $\mathrm{C}$ and $\mathrm{P}$ with time is then expressed as:

$\frac{\partial C_{C}}{\partial t}=D_{e, C} \nabla^{2} \cdot C_{C}-\mu_{C} C_{C}$

$\frac{\partial C_{P}}{\partial t}=D_{e, P} \nabla^{2} \cdot C_{P}-\mu_{P} C_{P}+S_{P}$

where $C_{P}$ and $C_{C}$ correspond to the concentration of $\mathrm{P}$ and $\mathrm{C}$ in the soil solution.

We consider the following boundary conditions:

Inner boundary condition: We assume that all roots in the model are identical, with surface $s=4 h z$. Roots release $\mathrm{C}$ from the root surface at constant rate $e_{C}$ and take up $\mathrm{P}$ at rate $U_{P}$ that follows a Michaelis-Menten equation depending on P concentration at the root surface (Eq. 5).

Outer boundary condition: to limit border effects, we consider a periodic outer boundary condition, i.e., assume that diffusion is soil occur on a torus in which top and bottom, as well as left and right edges of the soil volume are connected.

Due to the conservation of mass in the soil, at steady-state we thus have,

$n s U_{P}=D_{e, P} \nabla^{2} \cdot C_{P}-\mu_{P} C_{C}+S_{P}$

nse $_{C}=D_{e, C} \nabla^{2} \cdot C_{C}-\mu_{C} C_{C}$

where $s$ is the surface a root and $n$ is the number of roots in the modelled soil volume. 
Fig. S1: Diagram illustrating interactions between two roots in one dimension. Roots are separated by distance $2 d$. Horizontal arrows indicate the influences zones developed by root 1 and 2 while vertical dashed lines show their respective limits. In this diagram, the increase in supply occurs in the region shown as a thick horizontal line.

$2 d$

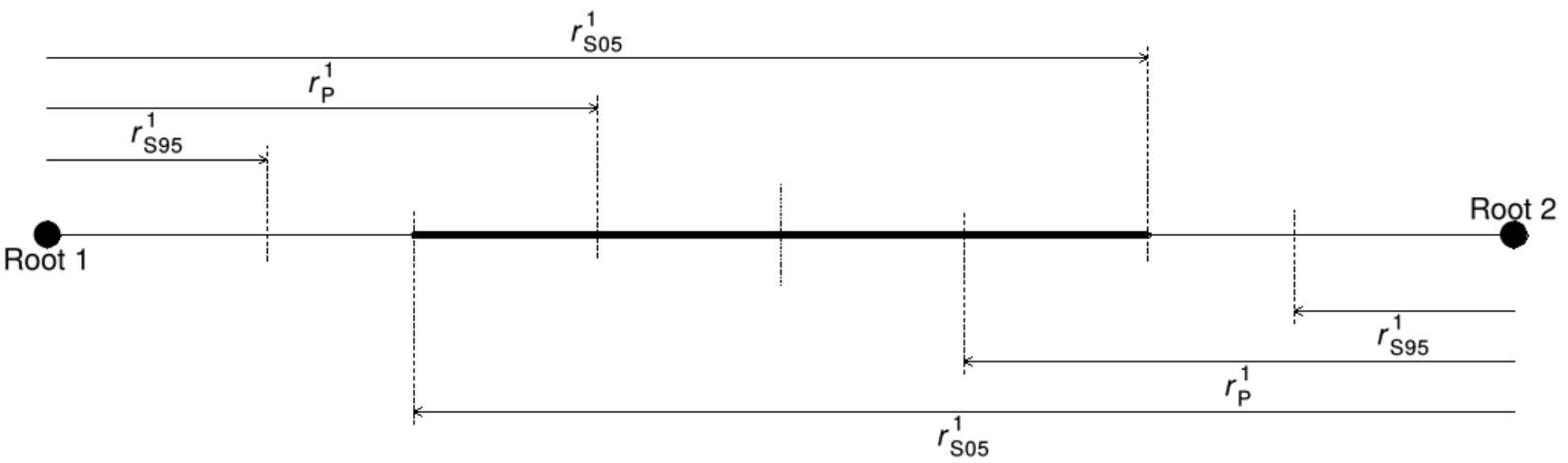


Fig S2: Phosphorus uptake efficiency (Eq. 9) relative to the uptake of a single root as a function of root density $\left(d_{R}\right.$, log scale). Symbols follow the same convention as in Figure 3 and 5 of the main text. Lines are coloured for $d_{R}$ values for which conditions $r_{95}^{1}<r_{\max }\left(d_{R}\right)$ (condition 2) and $2 * r^{1} 05$ $>r_{\max }\left(d_{R}\right)$ (condition 3 ) are met. Colours correspond to the value of $r_{P}{ }^{1} / r^{1}$ s95. The vertical line indicates the density over which condition 1 is not met. See main text for details.

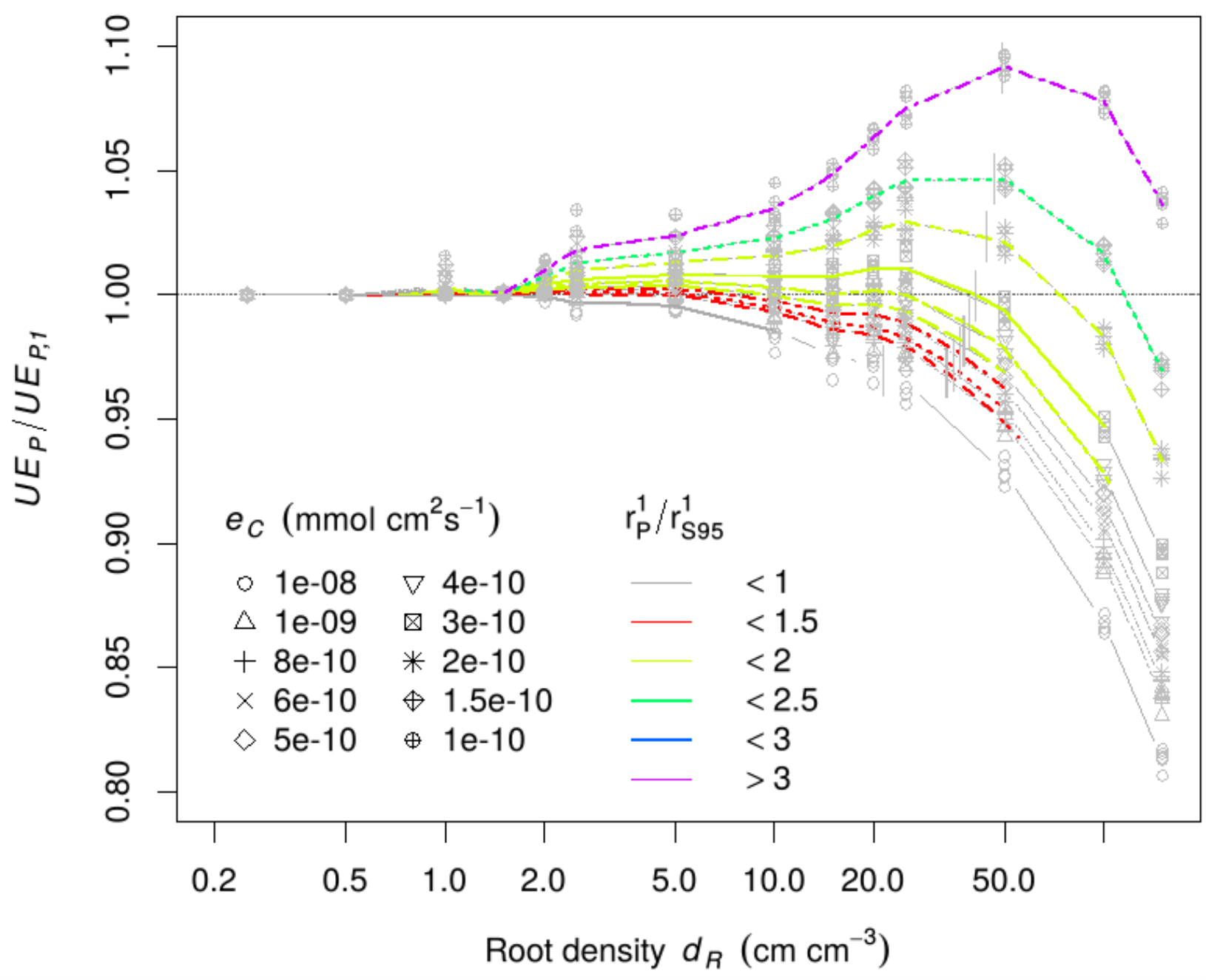


Table 1

\begin{tabular}{|c|c|c|c|}
\hline & Symbol & Definition & Units \\
\hline \multirow{6}{*}{ Phosphorus } & $C_{P}$ & P concentration in soil solution & 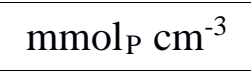 \\
\hline & $S_{P}$ & P supply & mmolp $\mathrm{s}^{-1}$ \\
\hline & $L_{P}$ & Nutrient losses & $\mathrm{mmol}_{\mathrm{P} \mathrm{s}} \mathrm{s}^{-1}$ \\
\hline & $A_{P}$ & Total plant absorption rate & $\mathrm{mmol}_{\mathrm{P}} \mathrm{s}^{-1}$ \\
\hline & $U E_{P}$ & Plant uptake efficiency & $\underset{1}{\operatorname{mmol}_{\mathrm{P}} \mathrm{cm}^{-1} \mathrm{~s}^{-}}$ \\
\hline & $\varepsilon$ & Nutrient uptake efficiency & $\mathrm{mol} \mathrm{P} / \mathrm{mol} \mathrm{C}$ \\
\hline \multirow[b]{2}{*}{ Exudate } & $C_{C}$ & Citrate concentration in soil solution & $\mathrm{mmol}_{\mathrm{C}} \mathrm{cm}^{-3}$ \\
\hline & $L_{C}$ & Exudate losses & $\mathrm{mmol}_{\mathrm{C}} \mathrm{s}^{-1}$ \\
\hline \multirow{3}{*}{$\begin{array}{l}\text { Root zone of } \\
\text { influence }\end{array}$} & $r^{1} C$ & Extent of citrate accumulation zone around a single root & $\mathrm{mm}$ \\
\hline & $\begin{array}{l}r^{1} s 05 \\
r^{1} s 95\end{array}$ & Extent of increased P supply zones around a single root & $\mathrm{mm}$ \\
\hline & $r^{1}{ }_{P}$ & Extent of P depletion zone around a single root & $\mathrm{mm}$ \\
\hline \multirow{3}{*}{ Territories } & $t_{C}$ & Extent of citrate accumulation when roots are in interaction & $\mathrm{mm}$ \\
\hline & $t_{S 95}, t_{S 05}$ & Extent of increased P supply when roots are in interaction & $\mathrm{mm}$ \\
\hline & $t_{P}$ & Extent of P depletion zone when roots are in interaction & $\mathrm{mm}$ \\
\hline
\end{tabular}


Table 2

\begin{tabular}{|c|c|c|}
\hline Symbol & Values & Ref. \\
\hline$\theta$ & $0.15 \mathrm{~cm}^{3} \mathrm{~cm}^{-3}$ & 7 \\
\hline$\theta_{\text {th }}$ & $0.1 \mathrm{~cm}^{3} \mathrm{~cm}^{-3}$ & 5 \\
\hline$\rho$ & $1.16 \mathrm{~g} \mathrm{~cm}^{3}$ & 7 \\
\hline$D_{l, P}$ & $8.210^{-6} \mathrm{~cm}^{2} \mathrm{~s}^{-1}$ & 8 \\
\hline$k_{d, P}$ & $82.6 \mathrm{~cm}^{3} \mathrm{~g}^{-1}$ & 5 \\
\hline$\mu_{P}$ & $10^{-3}-10^{-7} \mathrm{mmol}_{\mathrm{P}} \mathrm{s}^{-1}$ & \\
\hline$D_{l, C}$ & $6.210^{-6} \mathrm{~cm}^{2} \mathrm{~s}^{-1}$ & 8 \\
\hline$K_{d, C}$ & $4.4 \mathrm{~cm}^{3} \mathrm{~g}^{-1}$ & 1,5 \\
\hline$\mu_{C}$ & $10^{-5} \mathrm{mmol}_{\mathrm{C}} \mathrm{s}^{-1}$ & 2,3 \\
\hline$K_{S}$ & $10^{-5} \mathrm{mmol}_{\mathrm{C}} \mathrm{cm}^{-3}$ & 7 \\
\hline$S_{\min }$ & $10^{-12}-10^{-} \mathrm{mmol}_{\mathrm{P}} \mathrm{cm}^{-3} \mathrm{~s}^{-1}$ & 7 \\
\hline$S_{\max }$ & $510^{-10} \mathrm{mmol}_{\mathrm{P}} \mathrm{cm}^{-3} \mathrm{~s}^{-1}$ & 7 \\
\hline$n_{R}$ & $1-600$ unitless & \\
\hline$I_{\max }$ & 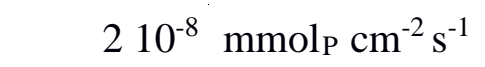 & 7 \\
\hline$K_{U}$ & $10^{-4} \mathrm{mmol}_{\mathrm{P}} \mathrm{cm}^{-3}$ & 7 \\
\hline$e_{C}$ & $10^{-10}-10^{-8} \mathrm{mmol}_{\mathrm{C}} \mathrm{cm}^{-2} \mathrm{~s}^{-1}$ & $1,2,3,4$ \\
\hline
\end{tabular}

1:Jones and Darrah (1994), 2:Kirk et al. (1999a), 3:Kirk et al. (1999b), 4:Nielsen et al. (1994),

5: Oburger et al. (2011), 6: Olesen et al. (2001), 7:Raynaud et al. (2008), 8:Vanysek (2000). 